\title{
Analysis of Subjective Perception of Effort (SPE) in Soccer Players Under-15 Using Reduced Game Training
}

\section{Fábio Luiz Andrade Moura ${ }^{1}$, Henrique Miguel ${ }^{1,2,4 *}$, Marcus Vinícius de Almeida Campos ${ }^{2}$ and Rafael Dramis Calixto $^{3}$}

${ }^{1}$ Department of Physical Education, Espirito Santo do Pinhal University Regional Center, Brazil

${ }^{2}$ Department of Physiacal Education, Euclides da Cunha College, Brazil

${ }^{3}$ Department of Physical Education, Machado Higher Education and Research Center, Brazil

${ }^{4}$ Department of Physical Education, José do Rosário Velano University, Brazil

Submission: June 05, 2018; Published: June 21, 2018

*Corresponding author: Henrique Miguel, Department of Physical Education Jose do Rosario Velano University, Brazil, Tel: +55 35 98804-6172; Email: prhmiguel@gmail.com

\section{Abstract}

Introduction: Training strategies and variations of their intensities applied to soccer are experts in discussions between coaches and physical educators. The use of Subjective Effort Perception (SEP) to classify individually a proposed training intensity in a reduced field (RF) is very useful for professionals in the field.

Objective: This study aimed to evaluate the PSE of boys from an under 15 soccer school in reduced game training, seeking to verify the intensity of the training.

Methodology: Ten students participated in 12 training sessions in a reduced field (5 + GK VS 5+ GK) with 30m x 40m footage. The PSE was verified post-training and the average was later analyzed by position of the players. Descriptive statistics were used in the study.

Results: The results showed that this form of training improves the technical part and dynamics of the tactical context of the game. An important factor observed in the research was the elevation of SEP levels in athletes with higher body mass indexes (BMI) and characteristics of defensive functions.

Conclusion: It is very important the understanding of the PSE in soccer, being able to guide professionals of the area not to generate an overload in training cycle, mainly in works that have different differences of volume and intensity of training.

Keywords: Training intensity; Reduced field; Sports training; Borg scale

\section{Introduction}

Football is a traditional and media sport in Brazil, thus becoming a popular and popular sports modality. Today it is practiced by men, women, and children [1]. Due to the great importance of this sport, studies aimed at measuring the intensity of the games' actions have been carried out. This leads to the possibility of organizing more coherent timelines during the application of the training cycle [2]. For Santos and Soares [3] football is an extremely complex game, from the physiological point of view, due to specific actions that show a typology of an effort of great diversity. In metabolic terms, they resort to clearly distinct energy sources.

During a soccer match, an athlete can perform several movements, such as: jumps, short starts, pikes, turns, in addition to contact with the ball, thus generating a need for a better physical and motor contribution, the need to use different systems energy in a game or training situation [4]. Barros and
Guerra [4], it analyzes, observed that one of the characteristics of soccer is the high intensity of the efforts in moments of short duration, brought by periods of less intensity and varied duration. Football is thus characterized as an intermittent activity and acyclic, where these factors are important to organize a training schedule appropriate to the group of players. When we talk about sports training, we know that in soccer it becomes a systematic activity that aims to provide morphological, metabolic and functional changes that tend to bring significant results in each athlete [5].

Within the process of sports training are the repetitions of outlined exercises. They are used to induce and create greater dexterity in the execution of specialized motor skills and also to develop structural and functional alterations that can maximize performance [5]. A preponderant aspect is a physical preparation within the context of the game. The physical factor, 
in this modality, has taken an important position in recent times, so the results obtained within a football match are directly related to the physical and technical training standards of the teams [6]. Because of these requirements within the game, it is known that the connection, between results and performance, is increasingly related to the performance of the player. Training that makes the athlete close to his physical limit began to undergo constant evolutions, reverting to an improvement of the abilities to be used by a soccer player who seeks high performance [7].

Knowing that the soccer player needs strength, in its different forms of manifestation, this factor comes to be of extreme value for a better performance of the same. When this force is not perfected and worked, it becomes a restrictive factor of great importance and makes it impossible to develop better within the modality and the adaptive cycle [8]. Impellizzeri et al. [9] propose a new theoretical model, based on the premise that the adaptations induced by training are due to the level of stress imposed on the organism. This factor is determined by the internal training load. Given this model, the magnitude of the internal load will be determined, mainly, by the prescribed training, which in turn is determined by the external load applied to it. To understand the level of effort of a player within the modality of football, we need to evaluate whether the training applied carries with it a high intensity causing tension, discomfort or fatigue. One of the meters to verify if these states were reached is an analysis of the PSE [9].

Within these high-intensity concepts, the reduced field games (JRC) have been widely used in soccer and demonstrate that it is possible to provoke overload stimuli that raise the PSE, provided that it has a dynamic independent of the degree of tactical and technical skills of the soccer player [10]. Evaluative studies of the PSE began in the 1950s, with the Swedish Gunnar Borg as its pioneer. In order to evaluate the physical effort, it was important that the individual had the capacity to interpret bodily sensations triggered by the proposed exercise [11]. The perception of effort according to Borg [12] refers to the intense muscular work involving a relatively great tension on the musculoskeletal, cardiovascular and pulmonary. Thus PSE measured after the exercise period can be defined as a psychophysical response generated and stored in the central nervous system, resulting from efferent neural impulses from the motor cortex [13]. The method used to measure PSE was proposed by Foster et al. [14], according to Figure 1, in order to quantify the training load. This methodology is based on a very simple questionnaire, with a single question: How was your training session?

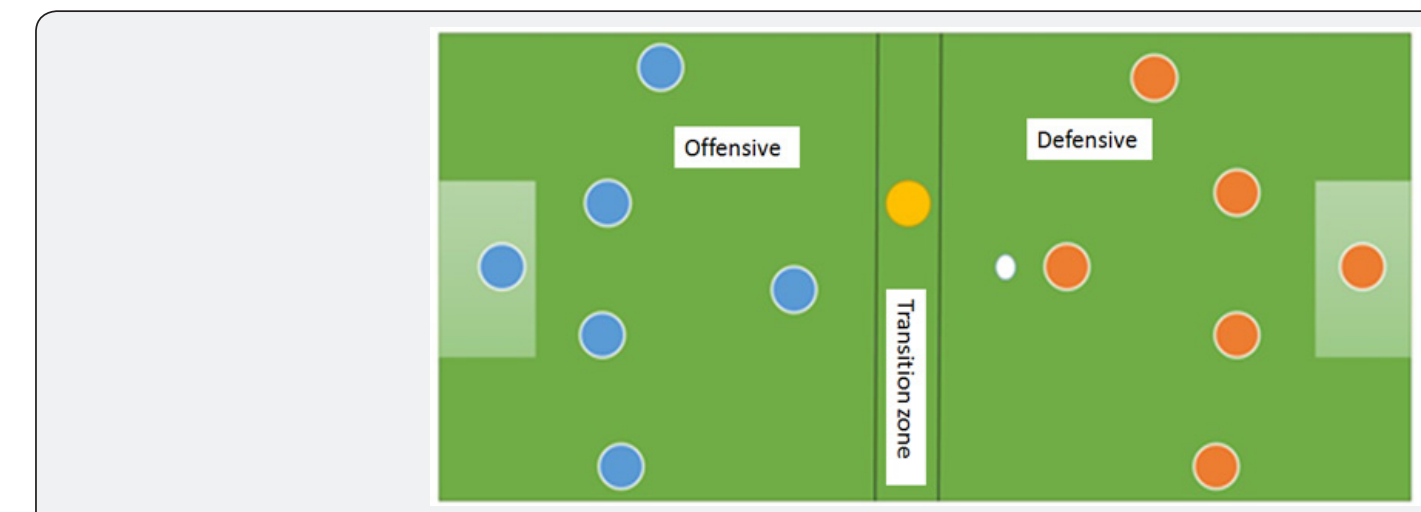

Figure 1: Reduced-field offensive/defensive transition.

After answering this question the student classifies the training in 0 to 10 according to his level of fatigue. The high level of the PSE, within the training process, allows evaluating the variation of the applied load involved with the alternation of the same, of external and internal form, with progressive order and that will provide to the athlete adaptations in the diverse organic systems. This incremental increment suggests the use of training loads that are increasingly higher and aim to promote stimuli for adaptations and overcompensation $[15,16]$. On the other hand, with the increase in intensity in the training sessions, undesirable effects may occur if there is inadequate planning of loads and recovery periods. This factor is called overtraining. Overtraining is directly linked to an athlete's performance drop in his or her specific mode. This fact happens due to the body's attempt to face stressors exerted by exercise and is perceived by some symptoms: irritability, lack of motivation, lack of appetite, loss of motivation among others [17].
From the existence of this picture, the athlete will suffer prolonged loss (months) of his / her sporting performance, somatizing severe alterations in the functional and psychological indicators [18]. According to the aforementioned evaluative parameters, the present study aims to analyze, within a process of reduced field training, directed to soccer, the PSE level that each player can reach. The results, obtained in the study, enabled professionals in the field of soccer to organize a training schedule with greater efficiency. The research helped to improve the training methods used in macrocycles, mesocycles, and microcycles, reducing the chance of injuries or injuries near competitions.

\section{Material and Methods}

The present study evaluated the Subjective Effort Perception (SPE) in students, from a soccer school in the city of Espirito Santo do Pinhal, in the sub 15 (fifteen) category. Data were collected 
from 10 (ten) students who had evaluated their PSE and thus verified the intensity reached individually. The selection process of the students was done by the selection of individuals who already had the habit of training and with constancy: 3 (three) days a week. They already had a satisfactory motor and physical repertoire for the research. The groups of players were divided into 2 (two) teams of 5 (five) men of line and 1 (one) goalkeeper in each goal $(5+\mathrm{GK}$ vs $5+\mathrm{GK})$, and underwent training in a reduced field. Space had natural grass and measures of thirty (30) x40 (forty) meters demarcated by signal disks. The training time was 45 (forty-five) minutes, simulating 1 (one) official game period.

Also, in the field of play, central lines were demarcated by dividing it into two parts and making possible the offensive and defensive transitions of each team in the game space (Table 1). Twelve (12) training sessions were conducted, which enabled the research and collection of comparative data between sessions, always considering the intensity of training for each student. After the end of activities, the group was stimulated to answer a single question: about the level of tiredness they perceived. The responses favored the analysis of SPE levels using the Borg scale ( 0 to 10 ) as a parameter. These levels were divided according to the intensity found in the scale used; the values were classified considering the perception of low-intensity levels up to the higher intensity levels.

Table 1: Borg CR10 scale.

\begin{tabular}{|c|c|}
\hline 0 & Resting \\
\hline 1 & Very easy \\
\hline 2 & Easy \\
\hline 3 & Moderate \\
\hline 4 & A little hard \\
\hline 5 & Difficult \\
\hline 6 & --- \\
\hline 7 & Very difficult \\
\hline 8 & --- \\
\hline 9 & --- \\
\hline 10 & Maximum \\
\hline
\end{tabular}

Source: Foster et al [14].

\section{Results}

The sample consisted of 10 (ten) individuals, of whom four midfielders, two lateral (one left and one right), three defenders and one striker. Table 2 presents the observed PSE results after 12 (twelve) training sessions per position and function of each player within the game system. After evaluating the training sessions, it was possible to perceive that the players who reached a higher average in the intensity category were the defenders. Another data collected in the level of results that comes to be important is about the relation of the PSE reached, BMI (body mass index) of each athlete and the positions within the system of the applied training.
Table 2: Subjective Effort Perception Analysis (SPE) by positions.

\begin{tabular}{|c|c|c|c|}
\hline Posição & N & \% & Mean SPE \\
\hline Defenders & 3 & 30 & 8,14 \\
\hline $\begin{array}{c}\text { Left/right } \\
\text { Backs }\end{array}$ & 2 & 20 & 7,25 \\
\hline Midfielder & 4 & 40 & 7,81 \\
\hline Forwards & 1 & 10 & 7,83 \\
\hline
\end{tabular}

\section{Discussion}

In this study, we aimed to verify the degree of intensity achieved in a reduced field transition game. According to the results presented, it can be seen that the highest levels of PSE achieved were by defensive players (defenders). This may have occurred due to the choice of the training model used in the sessions. Within this method of transition, of defensive/ offensive lines, it was possible to identify that the defenders were encouraged to travel greater distances to cross the offensive line of game making, in this way, its more compact team. What was also observed was that this attitude ended up being a requirement of the proposed game. Thus, the resulting compression of the used technique caused the PSE levels of the defenders in the field to rise when compared to the other players occupying other positions, as shown in Table 2.

Another important factor is that, within the specificity of the sport, the study in question pointed out that players, regardless of the position they occupy, should train with intensity and concentration very close to those of the game. Due to this, it was noticed that athletes, even in a reduced field, did not lose the tactical characteristics already assimilated, that is, they tried to maintain their proposed functions and positions in an official size game field (11x11 players). In a reduced field game (Figure 1), players require very large movement dynamics, as well as constant contact with the ball: this tends to intensify the actions and, if one considers the distance covered and the intensity imposed by the game, it is possible to verify that defenders and sides tend to position themselves further away from the transition line. In this way, these athletes tend to travel greater distances within the proposed game. Another explanatory and plausible discussion factor involves the particular characteristic of each athlete and how to behave before the game. Quarterbacks tend to stay less in contact with the ball and tend to position themselves on a defensive line of play, that is, closer to their goal.

Within the proposed dynamics all the participating athletes were stimulated to work in several positions of the game thus obtaining a greater variation of the movement of the same ones. This fact allowed a greater intensity in the proposal of transitions, where the analyzed ones had the objective of the constant changes of defensive / offensive field. In agreement with this statement and considering that training practices involving minor field play tend to provide a greater stimulus in relation to the tactical principles to be realized: space, defensive cover, concentration, and unit of play $[19,20]$. Going against the information in Table 3, it is observed that an important data is 
the BMI index (body mass index) of each athlete. When we relate the ideal proportion between fat mass and lean mass in soccer players, we do not yet have a good definition, but it has been deduced that the greater the amount of fat mass, the heavier the athlete tends to be and consequently the loss of other abilities: motor, aerobic resistance, speed and agility [21].

Table 3: Analysis of the correlation of BMI and position of each athlete.

\begin{tabular}{|c|c|c|c|c|}
\hline Athlete & Position & Weight (kg) & Height (m) & BMI \\
\hline 1 & Midfielder & 72,0 & 1,83 & 21,4 \\
\hline 2 & Defenders & 67,0 & 1,86 & 19,3 \\
\hline 3 & Left/right Backs & 75,0 & 1,81 & 22,8 \\
\hline 4 & Midfielder & 62,0 & 1,68 & 21,9 \\
\hline 5 & Forwards & 60,0 & 1,64 & 22,3 \\
\hline 6 & Defenders & 96,1 & 1,74 & 31,7 \\
\hline 7 & Midfielder & 62,0 & 1,73 & 20,7 \\
\hline 8 & Left/right Backs & 66,0 & 1,77 & 21,0 \\
\hline 9 & Defenders & 56,0 & 1,67 & 20,0 \\
\hline 10 & Midfielder & 59,0 & 1,69 & 20,6 \\
\hline Mean & \multirow{2}{*}{\multicolumn{2}{|c|}{$\begin{array}{l}67,5 \\
11,0\end{array}$}} & 1,74 & 22,1 \\
\hline Standard deviation & & & 0,07 & 3,5 \\
\hline
\end{tabular}

Due to these factors, anthropometric information and studies of this morphological dimension become essential as performance in sports becomes an important variable. In order to reach the peak of performance, the athlete must observe the influence or interference of the amount and distribution of body mass (fat and lean), because the variability of this distribution is important to obtain better results [22-24].

\section{Conclusion}

We can thus conclude that: players with defensive characteristics showed the highest indexes of PSE levels and also, BMI with higher values. In addition, the use of reduced field training provided an increase in game dynamics, especially when considering defensive/offensive transitions. It was also concluded that the fluency observed in the training was due to the increase in the need for compaction by the players caused mainly by the structuring used in the game. It was also observed that due to the use of the games in the reduced field, there was an increase of the intensity of the training, in addition to significant improvements of the technical levels: such as improvements of domain movements and short passes. A better tactical assimilation within the reduced field system was noted through this analysis. In the face of this, training in reduced fields with game transitions provided a great evolution in the issues that are important for the development cycle of athletes of this category.

\section{References}

1. T Stolen, K Chamari, C Catagna, U Wisloff (2005) Physiology of soccer: An update. Sports Medicine 35(6): 501-536.

2. N Eniseler (2005) Heart Rate and Blood Lactate Concentrations as Predictors of Physiological Load on Elite Soccer Players during Various Soccer Training Activities. Journal of Strength and Conditioning Research 19(4): 799-804.
3. PJ Santos, J Soares (2001) Capacidade aeróbia em futebolistas de elite em função da posição especifica no jogo. Revista Portuguesa de Ciências do Desporto 1(2): 142-149.

4. TL Barros, I Guerra (2004) Ciência do Futebol. Manole, Barueri.

5. A Viru (1995) Adaptations in sports training ( $1^{\text {st }}$ edn.); Informa Health Care, London.

6. MG Tubino (1993) Metodologia Científica do Treinamento Desportivo (11 ${ }^{\text {th }}$ edn.); Ibrasa, São Paulo, Brazil.

7. S Golomazov, B Shirva (1996) Futebol: Treino da Qualidade do Movimento para Atletas Jovens. Editora Aratebi, São Paulo, Brazil.

8. J Weineck (2000) Futebol Total. Phorte, São Paulo, Brazil.

9. FM Impellizzeri (2005) Physiological assessment of aerobic training in soccer. Journal of Sports Sciences 23(6): 583-592.

10. NM Stone, AE Kilding (2009) Aerobic conditioning for team sport athletes. Sports Medicine 39(8): 615-642.

11. BJ Noble, RJ Robertson (1996) Perceived Exertion. Human Kinetics, Illinois, USA.

12. G Borg (2000) Escala de Borg para dor e o esforço percebido (1 ${ }^{\text {st }}$ edn.); Manole, São Paulo, Brazil.

13. SM Marcora (2008) Locomotor muscle fatigue increases cardiorespiratory responses and reduces performance during intense cycling exercise independently from metabolic stress. American Journal of Physiology. Regulatory, Integrative and Comparative Physiology 294(3): 874-883.

14. C Foster (2001) A new approach to monitoring exercise training. Journal of Strength and Conditioning Research, Champaign 15(1): 109-115.

15. R Budgett (1998) Fatigue and underperformance in athletes: the overtraining syndrome. British Journal of Sports Medicine 32(2): 107110.

16. RW Fry, AR Morton, D Keast (1999) Periodization of training stress: A review. Canadian Journal of Sport Sciences Champaign 17(3): 234-240. 
17. M Gleeson (2002) M Bioquimical and immunological markers of overtraining. Journal of Sports Science and medicine 1(2): 31-41.

18. R Meeusen (2006) Prevention, diagnosis and treatment of the Overtraining Syndrome: ECSS Position Statement 'Task Force'. European Journal of Sport Science 6(1): 1-14.

19. IT Costa (2011) Relação entre a dimensão do campo de jogo e os comportamentos táticos do jogador de futebol. Rev bras Educ Fís Esporte 25(1): 79-96.

20. J Keogh (1999) The use of physical fitness scores and anthropometric data to predict selection in an elite under 18 Australian rules football team. Journal of Science and Medicine in Sport 2(2): 125-133.
21. TV Mantovani (2008) Composição corporal e limiar anaeróbio de jogadores de futebol das categorias de base. Revista Mackenzie de Educação Física e Esporte 7(1): 25-33.

22. JAR Santos (1999) Estudo comparativo, fisiológico, antropométrico e motor entre futebolistas de diferente nível competitivo. Rev paul Educ Fís 13(2): 146-159.

23. ML Foss, SJF Keteyian (2000) Bases fisiológicas do exercício e do esporte ( $6^{\text {st }}$ edn.); Guanabara Koogan, Rio de Janeiro, Brazil.

24. WL Prado (2006) Anthropometric profile and macronutrient intake in professional Brazilian soccer players according to their field positioning. Rev Bras Med Esporte 12(2): 61-65.

\section{Your next submission with Juniper Publishers} will reach you the below assets

- Quality Editorial service

- Swift Peer Review

- Reprints availability

- E-prints Service

- Manuscript Podcast for convenient understanding

- Global attainment for your research

- Manuscript accessibility in different formats ( Pdf, E-pub, Full Text, Audio)

- Unceasing customer service

Track the below URL for one-step submission https://juniperpublishers.com/online-submission.php 